\title{
Short communication: Milk meal pattern of dairy calves is affected by computer-controlled milk feeder set-up
}

\author{
M. B. Jensen ${ }^{1}$ \\ Department of Animal Health, Welfare and Nutrition, Faculty of Agricultural Sciences, University of Aarhus, DK-8830 Tjele, Denmark
}

\begin{abstract}
Ninety-six calves housed in groups of 8 were fed either a high milk allowance (heavy breeds $9.6 \mathrm{~L} / \mathrm{d}$; Jerseys $7.2 \mathrm{~L} / \mathrm{d}$ ) or a low milk allowance (heavy breeds $4.8 \mathrm{~L} / \mathrm{d}$; Jerseys $3.6 \mathrm{~L} / \mathrm{d}$ ) via a computer-controlled milk feeder. Half of the calves on each allowance could ingest the milk in 2 or more daily milk portions, whereas the other half could ingest the milk in 4 or more daily portions. Data were collected during 3 successive 14-d periods, the first period starting the day after introduction to the feeder at minimum $12 \mathrm{~d}$ of age. High-fed calves ingested their milk in 4.0 and 4.9 meals for a minimum of 2 and 4 portions, respectively, whereas low-fed calves ingested their milk in 2.4 and 4.4 meals for a minimum of 2 and 4 portions, respectively. Calves on a high milk allowance had fewer milk meals over time, whereas calves on a low milk allowance had the same number of milk meals throughout. Thus, the development from small and frequent milk meals to fewer and larger meals reported by studies of natural suckling was also found among high-fed calves on a computer-controlled milk feeder. Irrespectively of minimum number of milk portions, the low-fed calves had more unrewarded visits to the computer-controlled milk feeder, indicating that they were attempting to get more milk. The results of the present study suggest that offering a high milk allowance and avoiding restriction on meal pattern may result in a feeder use that more closely resembles natural suckling.
\end{abstract}

Key words: calf, computer-controlled milk feeder, meal pattern, milk allowance

Animals adjust their feeding behavior according to constraints such as the availability of food (Roguet et al., 1998) and the social environment (Nielsen, 1999). Automated and computer-controlled milk feeders also impose constraints and as these are becoming more widespread there is a need for understanding how the

Received September 25, 2008.

Accepted February 8, 2009.

${ }^{1}$ Corresponding author: MargitBak.Jensen@agrsci.dk calf interacts with the milk feeder and how various feeder characteristics constrain feeding behavior.

In the natural situation, a cow suckles her calf 5 to 11 times daily during the first few weeks, but the nursing frequency declines to 3 to 5 times per day during the following months (Nicol and Sharafeldin, 1975; Day et al., 1987). Initially, the cow initiates suckling, but after the first few weeks, suckling bouts are initiated more by the calf (Lidfors et al., 1994). The number of daily suckling bouts declines as the calf becomes older until the calf is weaned naturally between 8 and 12 mo of age (Hall, 1979; Reinhardt, 1980).

In the situation where a computer-controlled milk feeder provides the milk, calves are typically bucket-fed during the first days or weeks until being introduced to a computer-controlled milk feeder that may serve up to 30 calves. The computer-controlled milk feeder typically delivers a restricted amount of milk to individual calves in small portions at predetermined intervals. Visits to the feeder when there is no milk available to the calf is referred to as an unrewarded visit.

The default of most computer-controlled milk feeders is small and frequent milk portions, which is achieved by defining a high minimum number of portions (and a small maximum portion size) with pauses of a minimum interval between each portion (DeLaval, 2005). Thus, calves are typically offered a restricted milk allowance in a minimum number of milk portions of a maximum size. If the maximum portion size is larger than what the calf can ingest in one meal, the leftover milk is made available in a later additional portion. Thus, defining a large maximum portion size and, consequently, a small minimum number of portions should allow the individual calf some control over meal size and number of daily meals. This, however, is more likely to happen when the milk allowance is high, because at low milk allowances there is less milk to distribute. The hypothesis is that a small minimum number of portions of a large maximum portion size will cause calves to distribute their allowance over more milk meals, especially in calves fed a high milk allowance.

The aim of the present experiment was to investigate the effect of milk allowance and minimum number of 
milk portions on the size and number of milk meals in calves fed via a computer-controlled milk feeder.

Ninety-six male and female calves (31 Danish Holstein, 43 Danish Red, and 22 Jersey calves) born on the Cattle Research Centre at Foulum, Denmark, were allocated by birth order to 1 of 6 blocks. Within block, calves were allocated to 1 of 2 group pens within the same section balanced for birth order, sex, and breed. Each group pen $(4.65 \mathrm{~m} \times 4.35 \mathrm{~m})$ was straw bedded and had one computer-controlled milk feeder (HL100, Calvex, Højslev, Denmark). Calves were at least $12 \mathrm{~d}$ old when they were moved to these group pens. The first calves of a block were not moved until at least 4 calves were old enough to be moved at the same time ( 2 calves to each group pen). Calves had an average start weight of $47( \pm 1.0) \mathrm{kg}$ and a start age of median 14 (interquartile range 12 to 20 ) d.

Within pens, calves were allocated at random to 1 of 4 treatments: high milk allowance with a minimum of 2 milk portions; high milk allowance with a minimum of 4 milk portions; low milk allowance with a minimum of 2 milk portions; or low milk allowance with a minimum of 4 milk portions. Calves of the heavy breeds (Danish Holstein and Danish Red) were offered a milk allowance of either 9.6 or $4.8 \mathrm{~L} / \mathrm{d}$, whereas Jersey calves were offered either 7.2 or $3.6 \mathrm{~L} / \mathrm{d}$. For calves of the heavy breeds, the allowance of $9.6 \mathrm{~L}$ was divided into a minimum of 2 portions of $4.8 \mathrm{~L}$ maximum or a minimum of 4 portions of $2.4 \mathrm{~L}$ maximum, whereas the allowance of $4.8 \mathrm{~L}$ was divided into a minimum of 2 portions of 2.4 $\mathrm{L}$ maximum or a minimum of 4 portions of $1.2 \mathrm{~L}$ maximum. Similarly, for Jersey calves, the $7.2 \mathrm{~L}$ was divided into a minimum of 2 portions of $3.6 \mathrm{~L}$ maximum or a minimum of 4 portions of $1.8 \mathrm{~L}$ maximum, whereas the $3.6 \mathrm{~L}$ was divided into a minimum of 2 portions of $1.8 \mathrm{~L}$ maximum or a minimum of 4 portions of 1.0 or $0.8 \mathrm{~L}$ maximum. The number of milk portions was the minimum number of portions, and if calves consumed less than their allowed milk per portion, they could get the remaining milk in an additional portion. Each 24-h period was subdivided into two 12 -h feeding periods and, within each of these, calves could have one-half of their daily milk allowance in a minimum of either 1 or 2 milk portions according to treatment, but at least 30 min had to pass between successive milk portions. The computer-controlled milk feeder and the computer program controlling the milk feeder are described in more detail in Jensen (2004).

Before the introduction to the group pen, all calves were housed with their dam in a large straw-bedded pen for $24 \mathrm{~h}$ after birth and then in individual strawbedded calf hutches $(1.75 \mathrm{~m} \times 1.10 \mathrm{~m})$ with an outdoor yard $(1.60 \mathrm{~m} \times 1.00 \mathrm{~m})$. They were fed colostrum on $\mathrm{d}$ 2 to 4 and a mixture of whole milk and milk replacer via teat buckets on $\mathrm{d} 5$. All calves of the heavy breeds were offered $8 \mathrm{~L} / \mathrm{d}$, whereas all Jersey calves were offered $6 \mathrm{~L} / \mathrm{d}$. From d 6 and onward all milk was milk replacer [Friska Sød, DLG, Denmark, based on defatted milk powder $(60 \%)$, whey powder $(18 \%)$, and vegetable fat (18\%), and containing $24 \% \mathrm{CP}$ and $19 \%$ fat (145 $\mathrm{g}$ of replacer/L of water)]. In addition, multiparticle concentrates (Grøn Kalv Valset, DLG, Denmark; 18\% $\mathrm{CP}$ ) and hay were available ad libitum from d 2 and throughout the experimental period. Milk allowance from d 6 until being moved to the group pens was 8 or $6 \mathrm{~L} / \mathrm{d}$ for the heavy breeds and 6 or $4 \mathrm{~L} / \mathrm{d}$ for Jersey calves for high- and low-fed calves, respectively.

Calves were fed according to treatment from introduction to the group until the youngest calf in each group was $42 \mathrm{~d}$ old. Data were collected only during this period. After this period, all calves were gradually weaned, but no data were collected during gradual weaning.

Data were collected from the computer-controlled milk feeder for each calf during the first $42 \mathrm{~d}$ after introduction to the group pen, except for those calves that were introduced last. Calves were in the study for, on average, $40 \mathrm{~d}$ (range 30-42 d). For each calf, means were calculated over three 14-d periods (d 1-14, d 15-28, and d 29-42 in the group pen, respectively). These periods correspond to average ages of the calves of 14 to $27 \mathrm{~d}, 28$ to $41 \mathrm{~d}$, and 42 to $55 \mathrm{~d}$. Data from 7 calves (3 Danish Holstein and 4 Danish Red) were excluded from the data set because of technical problems in data collection (6 calves from treatment "high milk allowance with a minimum of 2 milk portions" and 1 calf from "low milk allowance with a minimum of 4 milk portions").

The computer-controlled feeder unit recorded and stored data regarding calves' use of the milk feeder and milk intake as described by Jensen (2004). For the present study, only frequencies of the different types of visits to the feeder (rewarded visits, unrewarded visits, and visits where the calf was entitled to milk but did not ingest any) and milk intake were included in the analysis.

Data were analyzed by variance component analysis using the MIXED procedure of SAS (Littell et al., 1996). The model for milk intake included the fixed effects of milk allowance, number of milk portions, period, milk allowance $\times$ number of milk portions, milk allowance $\times$ period, number of milk portions $\times$ period, milk allowance $\times$ number of milk portions $\times$ period, sex, breed, milk allowance $\times$ period $\times$ breed, and milk allowance $\times$ number of milk portions $\times$ breed. The model for the remaining variables included the fixed effects of milk allowance, number of milk portions, period, milk allowance $\times$ number of milk portions, milk allowance $\times$ pe- 
Table 1. Milk intake (L/d) of calves of the 3 breeds on high and low milk allowance in period 1, 2, and 3

\begin{tabular}{|c|c|c|c|c|}
\hline \multirow[b]{2}{*}{ Group } & \multicolumn{3}{|c|}{ Period $^{1}$} & \multirow[b]{2}{*}{ SEM } \\
\hline & $1(1-14 \mathrm{~d})$ & $2(15-28 d)$ & $3(29-42 \mathrm{~d})$ & \\
\hline \multicolumn{5}{|l|}{ Jersey $^{2}$} \\
\hline High milk & 6.76 & 6.75 & 7.04 & 0.25 \\
\hline Low milk & 3.61 & 3.61 & 3.61 & 0.21 \\
\hline \multicolumn{5}{|l|}{ Danish $\operatorname{Red}^{3}$} \\
\hline High milk & $7.45^{\mathrm{a}}$ & $8.32^{\mathrm{b}}$ & $9.07^{\mathrm{c}}$ & 0.17 \\
\hline Low milk & 4.82 & 4.81 & 4.81 & 0.18 \\
\hline \multicolumn{5}{|c|}{ Danish Holstein ${ }^{3}$} \\
\hline High milk & $8.11^{\mathrm{a}}$ & $8.31^{\mathrm{a}}$ & $8.93^{\mathrm{b}}$ & 0.23 \\
\hline Low milk & 4.79 & 4.79 & 4.83 & 0.19 \\
\hline
\end{tabular}

riod, number of milk portions $\times$ period, milk allowance $\times$ number of milk portions $\times$ period, sex, and breed. For random effects, both models included group and animal to account for the dependence between calves in a group and between repeated observations on the same calf. Satterthwaite's approximation was used to calculate the denominator degrees of freedom (Littell et al., 1996). When significant effects were found, contrasts were computed for comparing treatment means.

The calves were weighed at birth and when introduced to the group pen. Thereafter, the calves were weighed on the same day of the week every $14 \mathrm{~d}$. For each calf, average daily weight gain was calculated from introduction to the group pen until data collection from the computer-controlled milk feeder ended and this was used as input in the analysis for daily weight gain. Data were analyzed by variance component analysis using the MIXED procedure of SAS (Littell et al., 1996). The model included as fixed effects, milk allowance, number of portions, milk allowance $\times$ number of portions, sex, breed, and milk allowance $\times$ breed. As a covariate, the model included weight at introduction to the group pen (corrected for breed by subtracting the mean introduction weight within breed from the introduction weight), whereas block and group within block were included as random effects. Satterthwaite's approximation was used to calculate the denominator degrees of freedom (Littell et al., 1996). When significant effects were found, contrasts were computed for comparing treatment means.

As expected, high-fed calves had a higher average daily weight gain than low-fed calves [951 and 823 $( \pm 28)$ g, respectively; $P<0.001$ ], and calves of the heavy breeds had a higher daily weight gain than Jerseys $[944( \pm 28) \mathrm{g}, 980( \pm 32) \mathrm{g}$, and $737( \pm 35) \mathrm{g}$, for Danish Red, Danish Holstein, and Jersey, respectively; $P<0.001]$. Daily weight gain was higher in male than in female calves [921 and $853( \pm 27) \mathrm{g}$, respectively; $P$ $=0.05]$.

The low-fed calves ingested all of their allowance in all 3 periods, whereas the high-fed calves of the heavy breeds did not ingest all of their allowance in any of the periods. Milk intake increased over periods in the highfed calves of the heavy breeds (milk allowance $\times$ period $\times$ breed interaction; $P=0.01$; Table 1 ). Others have reported that Holstein calves with continuous access to milk ingested at least $10 \mathrm{~L}$ of milk daily at a similar age (Jasper and Weary, 2002; von Keyserlingk et al., 2006). In the present experiment, calves may have ingested more milk than recorded because volumes of $<0.2 \mathrm{~L}$ ingested during a rewarded visit were not recorded as intake, and the calf was categorized as being entitled to milk without ingesting any milk. High-fed calves had more visits where they were entitled to milk without apparently ingesting any milk than did low-fed calves, and in high-fed calves the frequency of this type of visit declined more over time [6.3, 3.3, 2.0 and 1.5, 0.6, 0.6 $( \pm 0.32)$ visits/d for high-fed calves in periods 1,2 , and 3 and low-fed calves in periods 1,2 , and 3 , respectively; $P<0.001]$.

As expected, the combination of a high milk allowance and a low minimum number of portions resulted in calves distributing their milk intake over more than the minimum number of portions. Among the calves on a high milk allowance, the daily number of rewarded visits (the daily number of meals) was 4 and $4.9( \pm 0.18)$, for a minimum number of milk portions of 2 and 4 , respectively. Among the calves on the low milk allowance, the number of meals was 2.41 and $4.38( \pm 0.19)$; that is, approximately 0.4 meals above the minimum number of milk portions (milk allowance $\times$ number of portions interaction; $P=0.001$ ). Thus, low-fed calves ingested close to the maximum portion size in each 
Table 2. Number of rewarded and unrewarded visits (frequency/d) of calves on high and low milk allowance in periods 1,2 , and 3

\begin{tabular}{|c|c|c|c|c|}
\hline \multirow[b]{2}{*}{ Item } & \multicolumn{3}{|c|}{ Period $^{1}$} & \multirow[b]{2}{*}{ SEM } \\
\hline & $1(1-14 \mathrm{~d})$ & $2(15-28 \mathrm{~d})$ & $3(29-42 \mathrm{~d})$ & \\
\hline \multicolumn{5}{|c|}{ Rewarded visits $^{2}$} \\
\hline High milk & $4.80^{\mathrm{a}}$ & $4.56^{\mathrm{a}}$ & $3.93^{\mathrm{b}}$ & 0.16 \\
\hline Low milk & 3.45 & 3.42 & 3.31 & 0.15 \\
\hline \multicolumn{5}{|c|}{ Unrewarded visits ${ }^{3}$} \\
\hline High milk & $5.64^{\mathrm{a}}$ & $7.42^{\mathrm{a}}$ & $10.88^{\mathrm{b}}$ & 1.69 \\
\hline Low milk & $34.20^{\mathrm{a}}$ & $32.53^{\mathrm{a}}$ & $26.79^{\mathrm{b}}$ & 1.58 \\
\hline
\end{tabular}

meal, whereas the high-fed calves with a low minimum number of portions distributed their allowance into twice as many meals than determined by the maximum portion size.

Among calves that were assigned to a minimum of 2 daily portions, the number of rewarded visits declined over periods $[3.57,3.28$, and $2.78( \pm 0.16)]$, but not among calves assigned to a minimum of 4 daily portions [4.68, 4.71, and $4.45( \pm 0.15)$; number of milk portions $\times$ period interaction; $P=0.01$. Overall, therefore, assigning calves to a minimum of 4 portions did not allow the calves to take fewer and larger meals over time.

An interaction with period was also found for milk allowance. Calves on a high milk allowance had fewer rewarded visits over periods, whereas among calves on a low milk allowance, the number of rewarded visits did not decrease over periods (Table $2 ; P<0.001$ ). Thus, the development from small and frequent meals to fewer and larger meals reported by studies of natural suckling (Day et al., 1987) was found only among the high-fed calves.

Previous studies of dairy calves fed ad libitum have reported daily milk intakes of approximately $10 \mathrm{~L}$ or more (e.g., Jasper and Weary, 2002; von Keyserlingk et al., 2006). Regarding meal patterns, von Keyserlingk et al. (2004) found the minimum interval between milk meals to be $40 \mathrm{~min}$ in calves fed ad libitum. Furthermore, they found that calves distributed an intake of approximately $14 \mathrm{~L}$ into 9 meals in a noncompetitive situation, whereas increasing competition for teat access reduced daily intake to $12 \mathrm{~L}$ without markedly reducing the number of meals. O'Driscoll et al. (2006) found that individually housed calves fed ad libitum ingested approximately $12 \mathrm{~L}$ in 10 meals from a computer-controlled milk feeder, whereas on the day of introduction to an established group of older calves, daily intake was reduced to $9 \mathrm{~L}$ distributed into 4 meals. Thus, the level of competition for access to the milk markedly affected meal patterns. Senn et al. (2000) found that calves fed ad libitum ingested approximately 5 daily meals of an average size of $2 \mathrm{~L}$ from a computer-controlled milk feeder in a situation with 11 calves per feeder. In the present study, 8 calves shared 1 milk feeder, and although milk was not ad libitum and the milk feeder forced calves to take a 30-min pause between successive meals, the high-fed calves had a similar number and size of meals as found in calves fed ad libitum. Senn et al. (2000) found that large meals were associated with longer post-meal intervals, which supports the hypothesis that high-fed calves may tend to pattern their intake in fewer and larger meals when given the opportunity.

The low-fed calves had more unrewarded visits to the milk feeder than the high-fed calves, but the trend over time was different for calves on the 2 milk allowances (Table 2; $P<0.001$ ). Previous studies have also found the occurrence of unrewarded visits to be lower in highfed calves (Jensen, 2006; De Paula Vieira et al., 2008) and unrewarded visits to decline over time irrespective of milk allowance (Jensen and Holm, 2003). In the present study the number of unrewarded visits decreased over periods in low-fed calves, whereas it increased over periods, starting from a very low level, in the high-fed calves. The discrepancy between the present study and the earlier study may be because of the high-fed calves receiving a higher milk allowance (9.6 rather than 8 L/d for heavy breeds).

It has been argued that calves should be fed a high milk allowance to achieve improved growth and health (Jasper and Weary, 2002). Although frequent small meals may be recommended in very young calves (Nussbaum et al., 2002), it may be suggested that older calves may be fed few large portions rather than many small portions. First, this better reflects the natural development in milk meal patterns. Second, it reduces milk feeder occupancy because many small portions re- 
sult in more nonnutritive sucking on the teat (Jensen, 2004) because of the sucking motivation being stimulated every time the calf ingests milk (Rushen and De Passillé, 1995). The default set-up of most commercially available computer-controlled milk feeders results in portions of less than $2 \mathrm{~L}$, and if the milk allowance is low, the meal size is likely to be the minimum portion size, as hungry calves ingest the milk as soon as it is available. The results presented here as well as earlier results (Senn et al., 2000; Jensen, 2004) suggest that it may be desirable to avoid milk portions of less than 2 L. Furthermore, for high-fed calves, it appears unnecessary to specify a minimum number of portions or a maximum portion size, as these calves distributed their allowance into 4 meals even if the minimum number of portions was set to 2 . We cannot exclude the possibility that calves may have taken more meals had the level of competition been lower. However, if fewer and smaller meals is a desired aim (e.g., for very young calves fed by computer-controlled milk feeder), reducing the level of competition rather than the predetermined portion size may be a better strategy.

For the low-fed calves, on the other hand, the number of milk meals was determined by the minimum number of portions allotted; that is, these calves appeared to finish the milk that was available at the time. Regardless of number of milk portions, the low-fed calves had many unrewarded visits. This reaction is interpreted as a sign of hunger (Jensen, 2006; De Paula Vieira et al., 2008) and illustrates that the way the calf uses the feeder is suboptimal from the calf's point of view when the milk allowance is low.

If calves' use of the milk feeders were to resemble the natural suckling situation more, then one suggestion would be to place no restriction on the minimum number of portions or the maximum portion size. A prerequisite for a more natural meal pattern may be a high milk allowance and a low level of competition. Furthermore, this may require modified programming of the computer-controlled milk feeder. For instance, accurate recording of milk intake from the feeders typically requires that calves finish the portion that is mixed for them, and they are more likely to do that when they have many small portions.

\section{ACKNOWLEDGMENTS}

The study was recommended by The Nordic Joint Committee for Agricultural Research and funded by the Danish Ministry of Food, Agriculture and Fisheries. Helle Møller Nielsen (Danish Cattle Research Centre) is acknowledged for taking care of the calves and Eric Luc Decker (Faculty of Agricultural Sciences, University of Aarhus) for help with data editing.

\section{REFERENCES}

DeLaval. 2005. DeLaval Automatic Calf Feeder CF 500 Combi Instruction Manual; version 1.02. DeLaval, Tumba, Sweden.

Day, M. L., K. Imakawa, A. C. Clutter, P. L. Wolfe, D. D. Zalesky, M. K. Nielsen, and J. E. Kinder. 1987. Suckling behavior of calves with dams varying in milk production. J. Anim. Sci. 65:1207-1212.

De Paula Vieira, A., V. Guesdon, A. M. De Passillé, M. A. G. Keyserlingk, and D. M. Weary. 2008. Behavioural indicators of hunger in dairy calves. Appl. Anim. Behav. Sci. 109:180-189.

Hall, S. J. G. 1979. Breed of the north: Studying the Chillingham wild cattle. Ark 6:72-79.

Jasper, J., and D. Weary. 2002. Effects of ad libitum milk intake on dairy calves. J. Dairy Sci. 85:3054-3058.

Jensen, M. B. 2004. Computer controlled milk feeding of dairy calves: The effects of number of calves per feeder and number of milk portions on use of feeder and social behavior. J. Dairy Sci. $87: 3428-3438$

Jensen, M. B. 2006. Computer-controlled milk feeding of group-housed calves, the effect of milk allowance and weaning type. J. Dairy Sci. 89:201-206.

Jensen, M. B., and L. Holm. 2003. The effect of milk flow rate and milk allowance on feeding related behaviour in dairy calves fed by computer controlled milk feeders. Appl. Anim. Behav. Sci. 82:87-100.

Lidfors, L., P. Jensen, and B. Algers. 1994. Suckling in free-ranging beef cattle-Temporal patterning of suckling bouts and effects of age and sex. Ethology 98:321-332.

Littell, R. C., G. A. Milliken, W. W. Stroup, and R. D. Wolfinger. 1996. SAS ${ }^{\circledast}$ System for Mixed Models. SAS Inst., Cary, NC.

Nicol, A. M., and M. A. Sharafeldin. 1975. Observations on the behaviour of single-suckled calves from birth to 120 days. Proc. N.Z. Soc. Anim. Prod. 35:221-230.

Nielsen, B. L. 1999. On the interpretation of feeding behaviour measures and the use of feeding rate as an indicator of social constraint. Appl. Anim. Behav. Sci. 63:79-91.

Nussbaum, A., G. Schiessler, H. M. Hammon, and J. W. Blum. 2002. Growth performance and metabolic and endocrine traits in calves pair-fed by bucket or by automate starting in the neonatal period. J. Anim. Sci. 80:1545-1555.

O'Driscoll, K., M. A. G. von Keyserlingk, and D. M. Weary. 2006. Effects of mixing on drinking and competitive behavior of dairy calves. J. Dairy Sci. 89:229-233.

Reinhardt, V. 1980. Untersuchung zum Sozialverhalten des Rindes. Birkhäuser Verlag, Basel, Switzerland.

Roguet, C., B. Dumont, and S. Prache. 1998. Selection and use of feeding sites and feeding stations by herbivores: A review. Ann. Zootech. 47:225-244.

Rushen, J., and A. M. De Passillé. 1995. The motivation of nonnutritive sucking in calves, Bos taurus. Anim. Behav. 49:15031510.

Senn, M., S. Gross-Lüem, H. Leuenberger, and W. Langhans. 2000. Meal patterns and meal induced metabolic changes in calves fed milk ad lib. Physiol. Behav. 70:189-195.

von Keyserlingk, M. A. G., L. Brusius, and D. M. Weary. 2004. Competition for teats and feeding behavior by group housed dairy calves. J. Dairy Sci. 87:4190-4194.

von Keyserlingk, M. A. G., F. Wolf, M. Hötzel, and D. M. Weary. 2006. Effects of continuous versus periodic milk availability on behavior and performance of daily calves . J. Dairy Sci. 89:2126-2131. 